\title{
An intensive intervention reduced cardiovascular and microvascular events in type 2 diabetes and microalbuminuria
}

Gaede P, Vedel P, Larsen N, et al. Multifactorial intervention and cardiovascular disease in patients with type 2 diabetes. $N$ Engl J Med 2003;348:383-93.

\section{QUESTION: In patients with type 2 diabetes and microalbuminuria, is a targeted intensive multifactorial intervention more effective than conventional treatment?}

\section{Design}

Randomised \{allocation concealed $*\}$, blinded \{data collectors and outcome assessors $\} \dagger^{*}$, controlled trial with mean follow up of 7.8 years (the Steno-2 Study).

\section{Setting}

A diabetes centre in Denmark.

\section{Patients}

160 patients (mean age 55 y) with type 2 diabetes and persistent microalbuminuria. Follow up was $81 \%$.

\section{Intervention}

80 patients were allocated to intensive treatment involving strict treatment goals with a stepwise implementation of behaviour modification (diet plan, exercise, and smoking cessation) and pharmacological therapy that targeted hyperglycaemia, hypertension, dyslipidaemia, microalbuminuria, and secondary prevention of cardiovascular disease with aspirin. 80 patients were allocated to conventional treatment of multiple risk factors from their general practitioner according to national guidelines.

\section{Main outcome measures}

The primary outcome was the composite endpoint of death from cardiovascular causes, nonfatal myocardial infarction, coronary artery bypass grafting, percutaneous coronary intervention, nonfatal stroke, amputation resulting from ischaemia, or vascular surgery for peripheral atherosclerotic artery disease.

Secondary outcomes were development of diabetic nephropathy, development or progression of diabetic retinopathy, and progression of neuropathy.

Source of funding: no external funding.

For correspondence: Dr O Pedersen, Steno Diabetes Center, Gentofte, Denmark. oluf@steno.dk

Abstract and commentary also appear in ACP Journal Club.

\section{Main results}

Analysis was by intention to treat. Intensive treatment was associated with a lower risk than conventional treatment for the primary composite outcome, development of diabetic nephropathy, development or progression of retinopathy, and progression of autonomic neuropathy (table). Groups did not differ for progression of peripheral neuropathy $(\mathrm{p}=0.66)$ or rates of $\geq 1$ minor hypoglycaemic event $(\mathrm{p}=0.50)$ or $\geq 1$ major hypoglycaemic event $(\mathrm{p}=0.12)$.

Intensive v convent up of 7.8 years:

\begin{tabular}{lllll} 
Outcomes & Intensive & Conventional & $\begin{array}{l}\text { Adjusted HR } \\
(95 \% \text { CI })\end{array}$ & NNT (CI) \\
\hline Composite endpoint§ & $24 \%$ & $44 \%$ & $0.47(0.22$ to 0.74$)$ & 5 (3 to 19$)$ \\
\hline Diabetic nephropathy & $24 \%$ & $47 \%$ & RRR (CI) & NNT (CI) \\
\hline Retinopathy & $52 \%$ & $71 \%$ & $61 \%(13$ to 83$)$ & 4 (3 to 14$)$ \\
\hline Autonomic neuropathy & $36 \%$ & $64 \%$ & $58 \%(14$ to 79$)$ & 5 (3 to 35$)$ \\
\hline
\end{tabular}

$\exists \mathrm{HR}=$ hazard ratio. Other abbreviations defined in glossary; RRR, NNT, and $\mathrm{Cl}$ calculated from data provided by author. HR adjusted for baseline characteristics.

$\S$ Composite endpoint of cardiovascular events.

\section{Conclusion}

In patients with type 2 diabetes and microalbuminuria, a targeted, long term, intensified, multifactorial intervention using behavioural modification and polypharmacological treatment was more effective than conventional treatment for reducing cardiovascular and microvascular events.

$$
\begin{aligned}
& \text { *See glossary. } \\
& \text { †Information provided by author. }
\end{aligned}
$$

\section{COMMENTARY}

In response to the diabetes epidemic, health systems may consider prioritising primary prevention, earlier detection, or aggressive intervention in patients with diabetes. National guidelines emphasise the latter approach based on expert opinion and evidence from studies of interventions that target single risk factors and measure process or surrogate endpoints. The impressive risk reduction for the composite cardiovascular endpoint seen in the intensively treated group of the Steno-2 study supports the strict targets in most current guidelines. However, these results may underestimate the true benefit of intensive treatment because the targets in the usual care group for blood pressure, haemoglobin $\mathrm{A}_{1}$, lipids, and aspirin use became more intensive over the course of the study, and $>50 \%$ of patients in this group were managed in specialist clinics at some point. Although it is unclear which intervention components were responsible for benefit, this study seems to justify widespread use of multiple medications to achieve treatment targets in patients at high risk.

How can we replicate these impressive results? The immediate challenge for healthcare systems is to identify approaches to assist patients with adherence to multiple medications. The next is to explore new ways of migrating elements of the specialist function that have traditionally resided in hospital based clinics into the community to support excellence in primary care led diabetes care. Examples of such new models of care include use of nurse case managers ${ }^{1}$ and electronically linked management systems between primary and secondary care. ${ }^{2}$ The concept of a Managed Clinical Network has been proposed as part of the National Service Framework for Diabetes in England and development of these networks may also provide new models for delivering diabetes care.

Sean F Dinneen, MD, FRCPI Addenbrookes Hospital Simon Griffin MSc, DM, FRCGP University of Cambridge Cambridge, UK

1 Aubert RE, Herman WH, Waters J, et al. Nurse case management to improve glycemic control in diabetic patients in a health maintenance organization. A randomized, controlled trial. Ann Intern Med 1998;129:605-12.

2 Montori VM, Dinneen SF, Gorman CA, et al. The impact of planned care and a diabetes electronic management system on community-based diabetes care: the Mayo Health System Diabetes Translation Project. Diabetes Care 2002;25:1952-7. 